\title{
Upregulated circZMIZ1 promotes the proliferation of prostate cancer cells and is a valuable marker in plasma
}

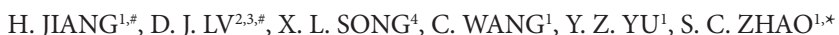

${ }^{1}$ Department of Urology, Nanfang Hospital, Southern Medical University/The First School of Clinical Medicine, Southern Medical University, Guangzhou 510515, China; ${ }^{2}$ Department of Urology, Minimally Invasive Surgery Center, The First Affiliated Hospital of Guangzhou Medical University, Guangzhou, China; ${ }^{3}$ Guangdong Key Laboratory of Urology, Guangzhou Institute of Urology, Guangzhou, China; ${ }^{4}$ Department of Radiation Oncology, Affiliated Cancer Hospital and Institute of Guangzhou Medical University, Guangzhou 510095, China

${ }^{*}$ Correspondence: zhaoshanchaosmu@sina.cn

${ }^{*}$ Contributed equally to this work.

Received February 13, 2019 / Accepted June 11, 2019

\begin{abstract}
Increasing evidences have proved that circular RNAs (circRNAs), identified as a specific kind of non-coding RNAs, play a potential critical role in tumorigenesis including prostate cancer. However, the function of circRNAs in human prostate cancer remains largely unknown. In this study, we demonstrated that the expression of circZMIZ1 was higher in plasma of human prostate cancer than the paired benign prostatic hyperplasia (BPH) patients' plasma. Moreover, in cultured prostate cancer cells, knockdown of circZMIZ1 inhibited cell proliferation and caused cell cycle arrest at G1. Mechanistically, we also showed that circZMIZ1 could increase the expression of androgen receptor (AR) and androgen receptor splice variant 7 (AR-V7), which may be partly contributed to the occurrence and development of prostate cancer. In conclusion, these results revealed that circZMIZ1 might serve as a novel biomarker and a treatment target for prostate cancer treatment.
\end{abstract}

Key words: circZMIZ1, prostate cancer, proliferation, $A R, A R-V 7$, double hydrogen testosterone

Prostate cancer $(\mathrm{PCa})$ is one of the most common malignant tumor among males on a global scale [1]. Despite low incidence, the morbidity of PCa has been increasing rapidly in China year by year, especially in the urban area $[2,3]$. On the other hand, $\mathrm{PCa}$ is characterized by an insidious onset, a slowly progressive course, and there is no obvious symptom in the early stage of PCa, hence, it usually progresses into an advanced stage. Although the early diagnosis and treatment of PCa have been improving, approximately $30 \%$ of patients will progress to advanced stages despite initial curative treatment [4], and up to $90 \%$ of those patients develop metastases in the bones $[5,6]$. However, the tumorigenesis and progression of prostate cancer remain unclear.

CircRNAs are a certain kind of non-coding RNAs, rather than splicing errors, generated by non-sequential back splicing through various mechanisms with covalently linked loops by free 3' and 5' ends [7]. Thus, their molecular structures are quite stable, and cannot be hydrolyzed by RNA enzyme. Recently, increasing studies have shown that circRNAs are intimately associated with various diseases, such as malignances [8-10], cardiovascular diseases [11], and central nervous system diseases [12]. It has been noted that inhibition of ZMIZ1 could impair the proliferation of PCa cell lines [13], and ZMIZ1 could enhance the transcriptional activity of androgen receptor by modulating the polyQ tract length [14]. According to CircBase database annotation, circZMIZ1 derives from exon 2, 3 and 4 of the ZMIZ1 gene locus (CircBase ID: hsa_circ_0005844, termed as circZMIZ1), which locates at chr10: 8087867180921890 (Figure 1A and Figure S1). We hypothesize that circZMIZ1 maybe plays physiological and pathological role in tumorigenesis and progression of PCa. However, the role of circZMIZ1 in PCa carcinogenesis has not been reported.

In our study, we assessed the expression level of circZMIZ1 in PCa cell lines and peripheral blood of prostate cancer patients by quantitative polymerase chain reaction (qRT-PCR). Subsequently, we investigated the functions and cellular localization of circZMIZ1 in PCa cell lines, and the relationship between circZMIZ1 and AR was explored. Overall, we intend to elucidate whether circZMIZ1 could be a promising biomarker and potential therapeutic target for PCa patients. 


\section{Patients and methods}

Patients. In the test group, the fasting plasma samples were obtained from 14 patients, who were diagnosed for PCa by prostate biopsy and surgical prostate tissue specimens. The patients were recruited from NanFang hospital of Southern Medical University from March 2018 to July 2018. In the control group, the fasting plasma samples from 14 age and gender matched healthy volunteers who were recruited from physical examination department, were obtained. Patients did not receive any endocrine therapy or radiotherapy before surgery and blood collection.

All patients consisted of $3 \mathrm{ml}$ of peripheral blood were collected from inpatient in with ethylenediaminetetraacetic acid (EDTA) coated tubes. The venous blood samples were centrifuged (Eppendorf 5415R) at $2000 \times \mathrm{g}$ for $10 \mathrm{~min}$ at $4^{\circ} \mathrm{C}$ to isolate plasma. Then the plasma collected from peripheral blood was immediately transferred to a RNase free tube and preserved at $-80^{\circ} \mathrm{C}$ until RNA isolation.

Before the recruitment of the study sample, the researchers obtained approval from the Human Research Ethics of Science and Technology Department of Southern Medical University, and all participants who took part in the study gave written informed consents.

Cell culture and treatment. The prostate cancer cell lines (DU145, C4-2, LNCaP, 22RV1), and normal human epithelial cell line (RWPE-1) were purchased from Cell Bank of Type Culture Collection, Chinese Academy of Science (Shanghai, China). These four prostate cancer lines were cultured in RPMI-1640 medium supplemented with 10\% FBS (Gibco, USA). To remove the lipotropic hormone, LNCaP cells were cultured in steroid hormone depleted RPMI-1640 medium containing 10\% charcoal-dextran stripped FBS (Invitrogen Life Technologies, Carlsbad, CA, USA ) [15] for 3 days, and were maintained at $37^{\circ} \mathrm{C}$ in $5 \% \mathrm{CO}_{2}$ incubator. The LNCaP cells were treated with double hydrogen testosterone (DHT) (Solarbio, Beijing, China) $(0.01,0.1,1,10,100$, and $1000 \mathrm{nM}$ ) for $24 \mathrm{~h}$ and $48 \mathrm{~h}$. All the cell lines were checked for mycoplasma contamination.

RNA extraction, quality control and reverse transcription. Total RNA was extracted from serum of patients with prostate cancer and healthy control groups with TRIzol LS Reagent (Invitrogen Life Technologies, Carlsbad, CA, USA), according to the protocol. Quantitation and estimation of total RNA samples purity were measured using NanoDrop ND-2000 (Thermo Scientific, DE, USA) spectrophotometer reading of A260/A280, and all the ratios of A260/A280 are in the range of $1.8-2.1$.

Total RNA of each sample (500 ng) was reversely transcribed using the $5 \times$ Prime $_{\text {Script }}{ }^{\mathrm{TM}}$ RT Master Mix (perfect Real Time) with $10 \mu \mathrm{l}$ of reaction solution (Takara, Dalian, China), following the manufacturer's instruction.

Quantitative real-time PCR. The quantitative real time PCR (qRT-PCR) analysis was carried out using SYBR Premix Ex Taq II (Takara Bio Inc.) with 7500 Real-Time PCR system (Applied Biosystems) according to the manufacturer's protocol. The divergent primers were applied to detect abundance of circZMIZ1. Glyceraldehyde 3-Phosphate Dehydrogenase (GAPDH) expression was used as an internal control. For quantitative results, the relative expression level of each circRNAs were calculated via the $2^{-\Delta \Delta C t}$ calculation. The probe sequences and optimized primer are listed in Table S1.

Treatment with Actinomycin and RNase R. To verify the structure of circRNA derived from back-splicing events, resulting in a circular, and not a linear RNA, we routinely use actinomycin D (Sigma, St. Louis, MO, USA) to block transcription and RNase R (Epicentre Biotechnologies, Madison, WI, USA) treatment to analyze the physical properties of these RNAs.

Actinomycin D (2 mg/ml) was used to prevent elongation of RNA chain by RNA polymerase [16], DMSO was used as negative control. $2 \mu \mathrm{g}$ of total RNA of C4-2 was treated with $10 \mathrm{U}$ RNase R (Epicenter, Technologies, Madison, WI, USA) at $37^{\circ} \mathrm{C}$ for $15 \mathrm{~min}$. The treated RNA was detected by qRT-PCR to analyze the expression level of circZMIZ1 and linear ZMIZ1 after treatment with actinomycin D and RNase R. 18S RNA was used as an internal control. The primers are listed in Table S1.

The isolation of nuclear and cytoplasmic RNA. To detect the expression of circZMIZ1 in nuclear and cytoplasmic, we used PARIS ${ }^{\text {m }}$ Kit (Ambion, Austin, TX, USA) to isolate nuclear and cytoplasmic according to the manufacturer's protocol. Briefly, fresh cultured cells $\left(1 \times 10^{7}\right.$ to $\left.2 \times 10^{7}\right)$ were collected, washed once in PBS, and kept on ice. The cells were resuspended in $500 \mu \mathrm{l}$ ice-cold cell fractionation buffer, then incubated on ice for $10 \mathrm{~min}$, and centrifuged at $500 \times \mathrm{g}$ for $5 \mathrm{~min}$ at $4^{\circ} \mathrm{C}$. The supernatants and the nuclear pellet were sub packaged in two RNase-free microfuge tubes. The nuclear pellet was lysed in ice-cold cell disruption buffer and placed on ice. An equal volume of $2 \times$ Lysis/Bing Solution was added to the same volume of $100 \%$ ethanol to the mixture. The sample mixture was transferred to a filter cartridge and washed once with $700 \mu \mathrm{l}$ wash solution 1 . The mixture was centrifuged for $1 \mathrm{~min}$. Then the samples were washed with $2 \times 500 \mu \mathrm{l}$ wash solution $2 / 3$ and centrifuged for $30 \mathrm{~s}$. Subsequently, the RNAs were eluted with $50 \mu \mathrm{l}$ of hot eluted solution $\left(95-100^{\circ} \mathrm{C}\right)$. At last, the ideal RNA samples were stored at $-80^{\circ} \mathrm{C}$ for further analysis and total RNA was determined by qRT-PCR. U6 and GAPDH were used as nuclear and cytoplasmic markers, respectively. The primers are listed in Table S1.

RNA fluorescence in situ hybridization (FISH). Cy3-labeled circZMIZ1 probes (sequence available upon request) was designed and synthesized by RiboBio (Guangzhou, China). C4-2 cells were harvested in exponential growth phase and about $80-90 \%$ confluency at the time of fixation. After pre-hybridization in a hybridization buffer, C4-2 cells were hybridized in a dark moist chamber for $12 \mathrm{~h}$ at $37^{\circ} \mathrm{C}$ with circZMIZ1 FISH Probe Mix provided by the kit. 
After washing, cell nuclei were stained with 4, 6-diamidino2-phenylindole (DAPI). Fluorescent images were obtained using a confocal microscope (Carl Zeiss, LSM 510, Wetzlar, Germany).

Transient RNA interference. To investigate the function of circZMIZ1, small interference RNA (siRNA) (RiboBio, Guangzhou, China) was used to silence the expression of circZMIZ1, the sequence of circZMIZ1 was obtained from article [17]. We designed specific siRNA targeting the backsplice junction of circZMIZ1 (RiboBio, Guangzhou, China; Table S1). Transient transfection was performed using Lipofectamine 3000 reagent (Life Technologies, Carlsbad, CA, USA) according to the manufacturer's recommendation. The expression of AR and AR-V7 were detected by qRT-PCR, siAR sequence was from report by Lorenzo et al. [18]. The sequences used are shown in Table S1.

Preparation and electrophoretic analysis of Genomic DNA. In DNA agarose gel electrophoresis, DNA was extracted from prostate cancer cells and plasma samples by using EasyPure Genomic DNA Kit (TransGen-EasyPure, Beijing, China). Extracted DNA samples were amplified by polymerase chain reaction (PCR) and the products were analyzed with Bio RAD. The PCR reaction mixture contained $12.5 \mu \mathrm{l}$ of $2 \times \mathrm{Taq}$ PCR Master Mix, $1 \mu \mathrm{l}$ of each primer $(10 \mu \mathrm{M}), 1 \mu \mathrm{l}$ of DNA template $(<1 \mu \mathrm{g})$, and $9.5 \mu$ l of nucleasefree water for a total volume of $25 \mu$ l. Thermal cycling was conducted in the temperature as follows: initial denaturation at $94^{\circ} \mathrm{C}$ for $3 \mathrm{~min}$; followed by 30 cycles of denaturation $94^{\circ} \mathrm{C}$ for $30 \mathrm{~s}$; annealing, $55^{\circ} \mathrm{C}$ for $30 \mathrm{~s}$; elongation, $72^{\circ} \mathrm{C}$ for $1 \mathrm{~min}$, and with a final extension at $72^{\circ} \mathrm{C}$ for $5 \mathrm{~min}$ and hold at $4{ }^{\circ} \mathrm{C}$. The primers are listed in Table S1.

The samples were separated on a $2 \%$ agarose gel containing $0.5 \mathrm{mg} / \mathrm{ml}$ ethidium bromide, and electrophoresis was performed at $100 \mathrm{~V}$ for $30 \mathrm{~min}$. $5 \mu \mathrm{l}$ of DI2000 (Sigma, St. Louis, MO, USA) was used as DNA molecular weight marker. They were then photographed on Bio-Rad Molecular Imager Gel Doc ${ }^{\text {Th }}$ XR + Imaging System (Hercules, CA, USA).

Cell proliferation assay. To evaluate the proliferation of C4-2 and LNCaP cells, the cell counting kit-8 (CCK-8) assay (Dojindo Laboratories, Kumamoto, Japan) was used to measure the cellular proliferation. Transfected cells were seeded into 96 -well plates $\left(3 \times 10^{3}\right.$ cells per well) and incubated for $0,24,48,72,96$, and $120 \mathrm{~h}$, respectively, $10 \mu \mathrm{l}$ of CCK-8 reagent was added to each well and the incubation continued for another $2 \mathrm{~h}$ in an incubator at $37^{\circ} \mathrm{C}$ and $5 \% \mathrm{CO}_{2}$, and the optical density (OD) value at $450 \mathrm{~nm}$ was detected in each well $(\mathrm{EL} \times 808$; Bio Tek, Winooski, VT, USA). The assay was performed in triplicate.

Cell cycle analysis. Cell cycle analysis was executed as described previously $[19,20]$. Briefly, we collected the transfected cells by centrifugation $(500 \times \mathrm{g}, 5 \mathrm{~min})$. The cell number was determined by counting in a hemocytometer, and the final cells concentration was adjusted to approximately $2 \times 10^{6}$ per milliliter. Cells were fixed with absolute ethanol (final concentration approx. 70\%), and RNase A was used to get rid of RNAs contamination. Then, C4-2 and DU145 cells were incubated with PBS containing $0.5 \%$ Triton X100, and propidium iodide (PI, final concentration, $50 \mathrm{ng} / \mathrm{ml}$, Sigma, St Louis, MO, USA) was used to stain DNA for $15 \mathrm{~min}$ at room temperature in the dark. After staining with PI, the cell cycle distribution was measured by flow cytometry (Beckman FC500, Los Angeles, CA, USA). The data were presented as the percentages of cells at each phase.

5-Ethynyl-2-deoxyuridine (EdU) incorporation assay. The EdU assay was performed using a Cell-Light ${ }^{\mathrm{tm}}$ EdU DNA cell proliferation Detection Kit (RiboBio, Shanghai, China). DU145 cells were seeded in each well of 96-well plates for transfection with sicircZMIZ1 and negative control (NC). After incubation at $37^{\circ} \mathrm{C}$ and $5 \% \mathrm{CO}_{2}$ for 2 days, $\mathrm{EdU}(50 \mu \mathrm{M} /$ well) was added for $2 \mathrm{~h}$, and then the cells were fixed with $4 \%$ paraformaldehyde for $20 \mathrm{~min}$. Apollo Dye Solution (RiboBio, Shanghai, China) for proliferating cells was used for staining at room temperature for $30 \mathrm{~min}$. After washing three times with PBS, Hoechst 33342 was used to stain nuclei acids for $30 \mathrm{~min}$ at room temperature. Images were observed with an Olympus FS $\times 100$ microscope (Olympus, Tokyo, Japan), and the percentage of EdU positive cells were counted. The experiment was carried out in triplicate.

Statistical analysis. The data were presented as mean \pm standard deviation (SD). All experimental data were performed by Statistical Program for Social Sciences (SPSS) 19.0 Software (SPSS, Chicago, IL, USA) and GraghPad Prism 6.0 (GraghPad Software Inc., San Diego, CA, USA). Differences of circZMIZ1 levels among groups were performed using two-tailed Student's t-test. The correlation between two variables was performed with Pearson linear correlation. A $\mathrm{p}<0.05$ was considered to have significant difference. ${ }^{*} \mathrm{p}<0.05,{ }^{* *} \mathrm{p}<0.01,{ }^{* * *} \mathrm{p}<0.001$.

\section{Results}

CircZMIZ1 expression is upregulated in PCa patients' peripheral blood and cell lines. CircZMIZ1 was generated from exon 6 and exon7 of ZMIZ1 gene as illustrated in scheme (Figure 1A and Figure S1). To determine whether circRNAs are differently expressed in PCa patients and normal control, we first carried out qRT-PCR analysis to identify expression profiles in human PCa cell lines. Five commonly used PCa cell lines were selected for in vitro study (Figure 1B), including RWPE-1, C4-2, DU145, LNCaP and 22Rv1 cells. We found that the expression level of circZMIZ1 was significantly upregulated in DU145, LNCaP and C4-2 cell lines compared to RWPE-1. Subsequently, we demonstrated that circZMIZ1 was considerably higher in PCa patients' plasma samples than in corresponding normal control (Figures 1C and 1D). These results indicated that circZMIZ1 may play an oncogenic role in PCa.

Characteristic of circZMIZ1. The location of circRNA is vital for its function. Interestingly, as showed in Figures 2A and $2 \mathrm{~B}$, we found circZMIZ1 distributed almost equally 
A

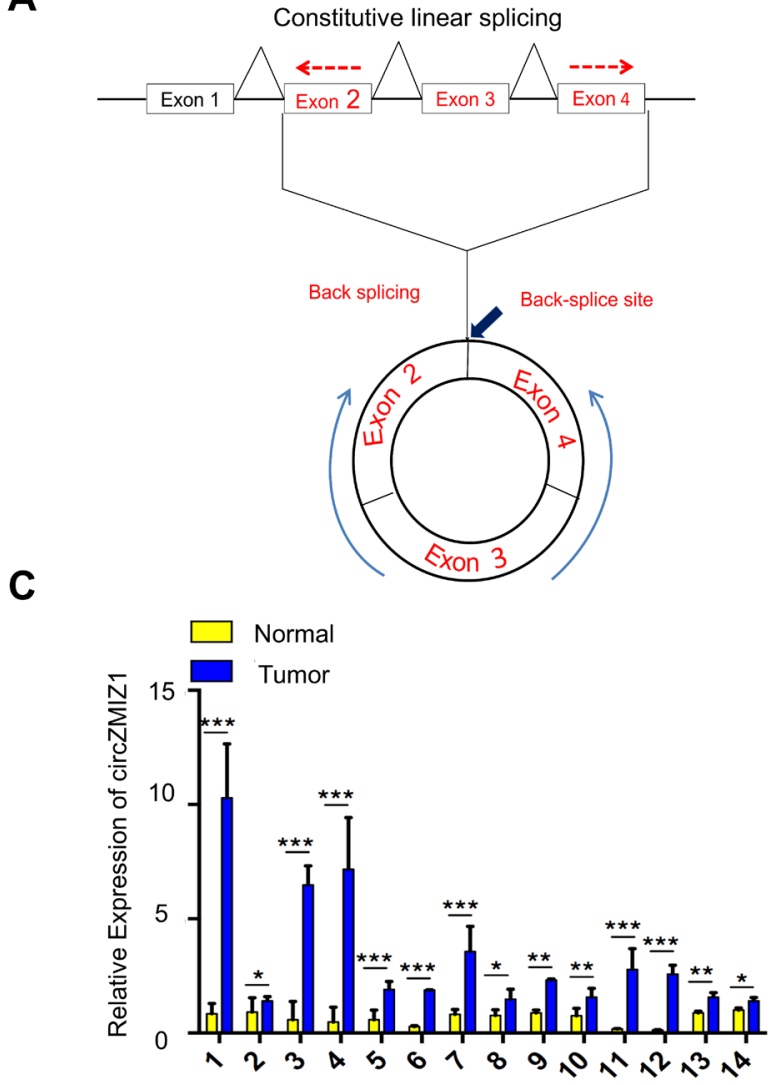

B

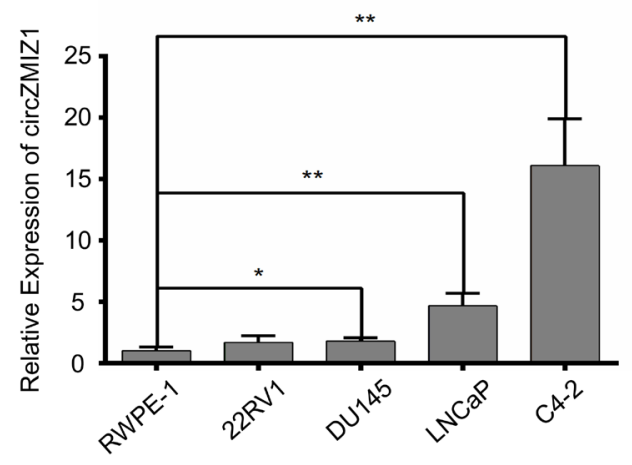

D

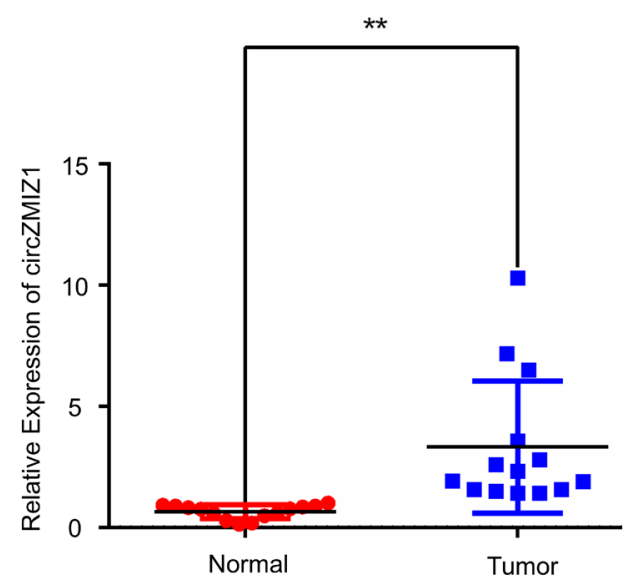

Figure 1. Differential expression profiles of circZMIZ1 in prostate cancer. A) Scheme illustrating the production of circZMIZ1. The back-splicing site of circZMIZ1 is shown with a red arrow. B) Relative expression level of circZMIZ1 was measured in normal human epithelial cell line RWPE-1 and four prostate cancer lines, LNCaP, DU145, 22RV1 and C4-2 by qRT-PCR. C and D) The expression of circZMIZ1 was observed by qRT-PCR in 14 prostate cancer patients blood samples compared with their corresponding normal control. GAPDH was used as internal control. Data are presented as the mean \pm SD $(n=3)$. Statistically significant was identified as $p<0.05$. $\left({ }^{\star} p<0.05,{ }^{* *} p<0.01\right)$. Student's t test was utilized.

between the cytoplasm and nucleus in PCa cells. This localization is different from the circRNAs generated from exons, since these are mainly distributed in cytoplasm $[21,22]$. The different circZMIZ1 expression may regulate the function in PCa progression and transcription. As mentioned previously, circRNAs are circular shape and covalently closed, often generated from back-splicing of protein-coding exon. So, we designed divergent and convergent primer to amplify circZMIZ1 and linear ZMIZ1 mRNA. The cDNA and gDNA templates were extracted from two plasma samples and C4-2, DU145 cell lines. As shown in Figure 2C, we found that circZMIZ1 were amplified by divergent primers in cDNA but not in gDNA. The total RNA of DU145 cells was separated at the indicated time point after treatment with actinomycin $\mathrm{D}$ and the total RNA of C4-2 with RNase R, then analyzed by using qRT-PCR. As shown in Figures 2D and 2E, we found that the linear ZMIZ1 was digested by RNase R. However, circZMIZ1 was resistant to digestion by the 3'-5'exonuclease RNase $\mathrm{R}$, meaning that circZMIZ1 is more stable than the linear RNA, and sicircZMIZ1, which was designed, had no effect on linear ZMIZ1.
CircZMIZ1 knockdown inhibits the proliferation of PCa cells in vivo. We observed that circZMIZ1 was significantly increased in peripheral blood compared to the matched controls. Hence siRNA targeting circZMIZ1 was transfected to knockdown the expression of circZMIZ1, as shown in Figure 3A. siRNA dramatically silenced circZMIZ1 whereas linear ZMIZ1 didn't changed. Subsequently, functional experiments were carried out to reveal the effect of circZMIZ1 in the development and progression of PCa. CCK-8 assay showed that knockdown of circZMIZ1 markedly suppressed proliferation rate in both DU145 and C4-2 cells compared with control cells (Figure 3B). The EdU cell proliferation assay also showed that the proliferation of PCa DU145 cells was inhibited by transfection with knockdown of circZMIZ1 (Figure 3C). Taken together, these results reveal that circZMIZ1 may modulate the growth of PCa cells.

Silencing of circZMIZ1 arrests cell cycle. We next investigated the role of circZMIZ1 on the cell cycle distribution of DU145 and C4-2 cells via flow cytometry analysis. We noted that silencing of circZMIZ1 could obviously increase the proportion of cells in G1-phase from $51.66 \%$ to $71.44 \%$, and 


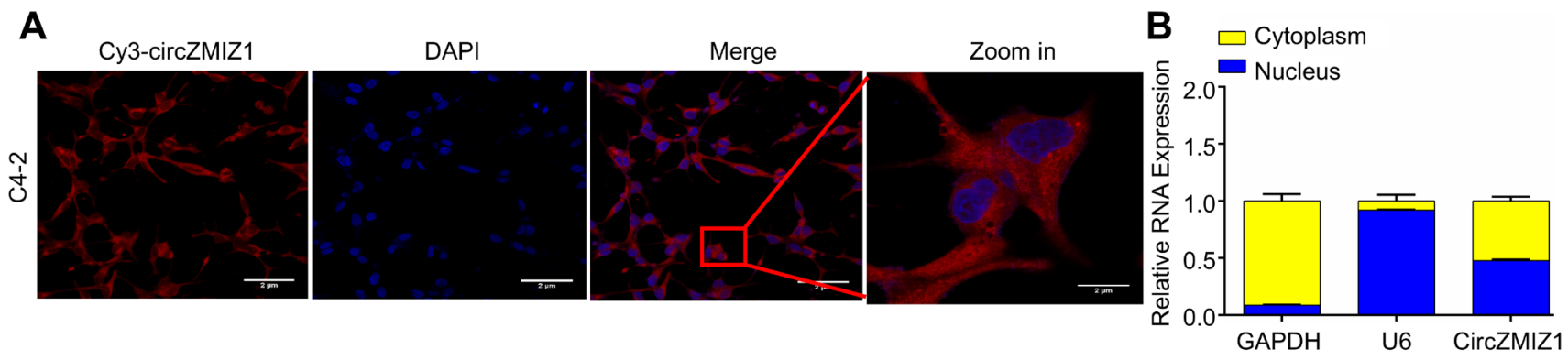

C
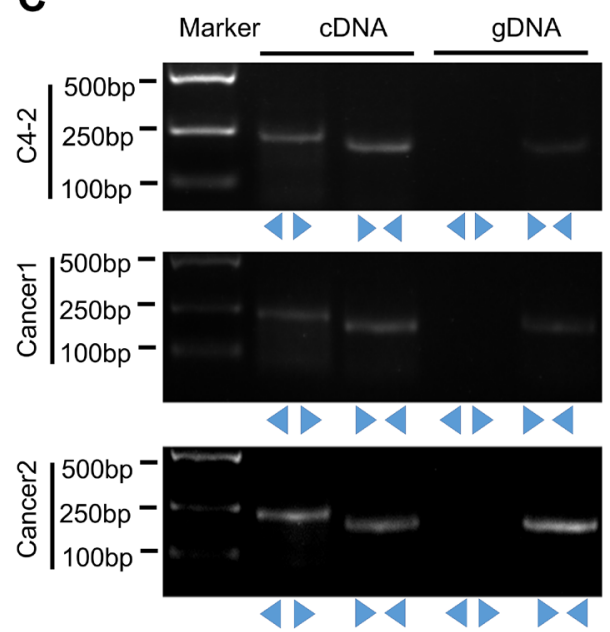

D

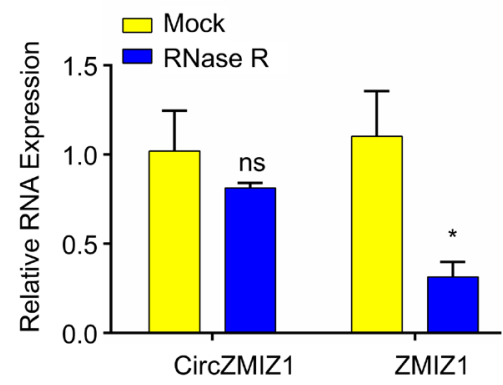

$\mathbf{E}$

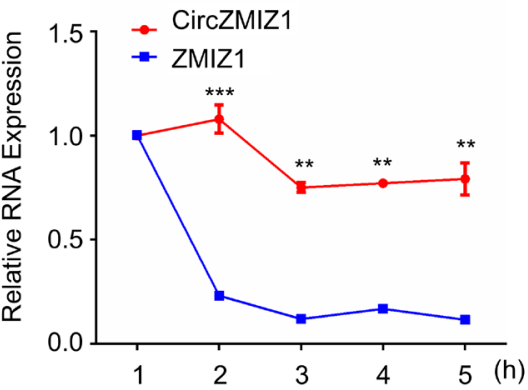

Figure 2. Characterization of circZMIZ1 in human prostate cancer cells. A) RNA fluorescence in situ hybridization (FISH). Nuclei were stained with DAPI. Scale bar, $2 \mu \mathrm{m}$. B) qRT-PCR analysis of circZMIZ1 in prostate cancer cells, U6 and GAPDH served as positive controls in the nucleus and cytoplasm, respectively. C) Divergent primer amplified circZMIZ1 in cDNA but gDNA in C4-2 cell lines and two prostate cancer patients. D) qRT-PCR analysis of circZMZI1 and ZMIZ1 mRNA after treatment with RNase R in C4-2 cells. E) qRT-PCR analysis of circZMZI1 and ZMIZ1 mRNA after treatment with Actinomycin D at the indicated time points in C4-2 cells, 18S RNA was used as internal control.

the cells in S-phase decreased from $31.79 \%$ to $21.49 \%$ in C4-2 cells compared to the NC cells (Figure 3D). Similar findings were observed in the DU145 cells, as shown in Figure 3E. These results clearly indicate that circZMIZ1 may play a major role in cell cycle progression.

Androgen treatments promotes the expression level of circZMIZ1. As we know, androgen strongly correlates with $\mathrm{PCa}$, and we have found that circZMIZ1 was significantly upregulated in PCa cell lines. To further investigate the relationship between androgen and circZMIZ1, we analyzed the level of circZMIZ1 under treatment with different concentration of DHT in the LNCaP cell line. As showed in Figures $4 \mathrm{~A}$ and $4 \mathrm{~B}$, we noted that expression of circZMIZ1 could be induced by DHT treatment in LNCaP cells, and there is an obvious time and dose dependence trend. Meanwhile, when AR expression was silenced by siAR, we found that level of circZMIZ1 was markedly decreased (Figure 4C). In addition, the expression of $\mathrm{AR}$ was positively correlated with the expression of circZMIZ1 in LNCaP cell line (Figure 4D). In conclusion, these results indicated that circZMIZ1 is closely associated with androgen and androgen receptor.
Silence of circZMIZ1 downregulates the level of AR-V7. As previously mentioned, circZMIZ1 is encoded by the gene ZMIZ1, which could enhance the transcriptional activity of androgen receptor [14]. Hence, we hypothesized that circZMIZ1 may be correlated with AR. To prove this, we measured the expression level of both AR and AR-V7 mRNA in LNCaP cells using qRT-PCR. Meanwhile, as shown in Figure 4E, we observed that the expression of AR and AR-V7 mRNA was dramatically downregulated in LNCaP cells treated with sicircZMIZ1. These results further revealed that the expression of circZMIZ1 might modulate expression level of AR and AR-V7. Moreover, circZMIZ1 may play a key role in the development and progression of castration-resistant prostate cancer (CRPC), which is strongly correlated with activation of AR-V7 [23].

\section{Discussion}

ZMIZ1, originally named ZIMP10 or RAI17, is a transcriptional co-activator, which shares a highly conserved SP-RING/Miz domain of Protein Inhibitor of Activated 
A

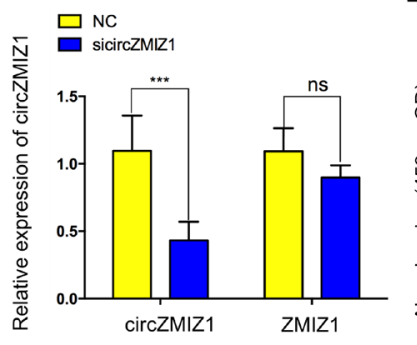

C
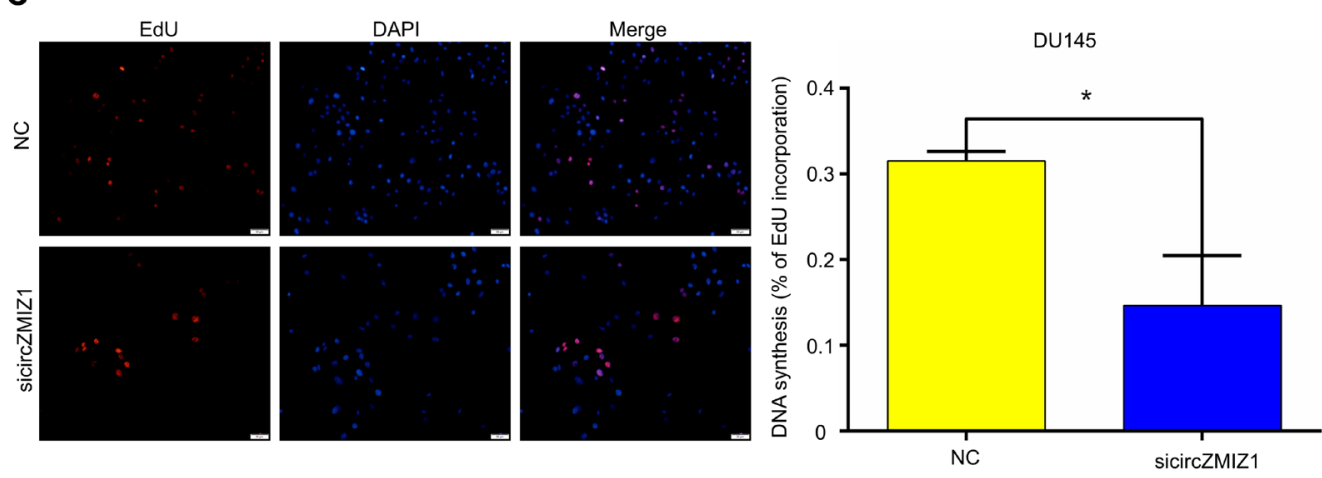

D

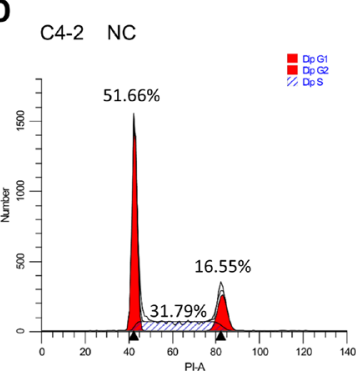

E

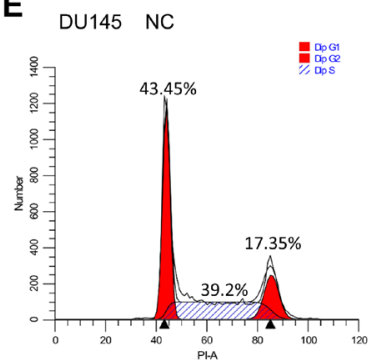

B
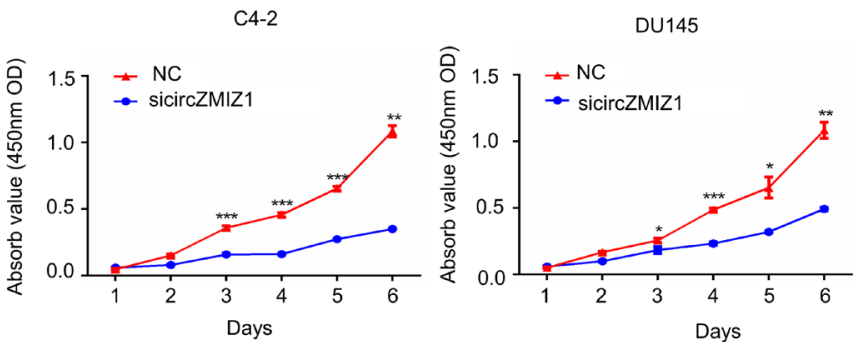

C4-2

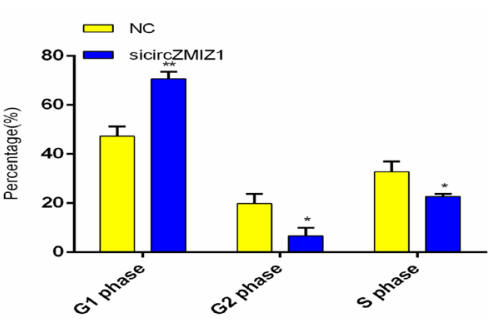

DU145

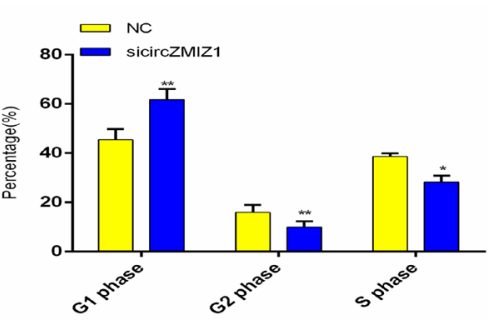

Figure 3. Silencing of circZMIZ1 inhibits human prostate cancer cell proliferation. A) The expression of linear ZMIZ1 and circZMZI1 was tested after treated with sicircZMIZ1 by qRT-PCR. B) Cell proliferation was tested with CCK-8 assay in C4-2 and DU145 cells at indicated time points. C) Observation of DNA synthesis of DU145 transfected with sicircZMIZ1 by EdU (5-Ethynyl-2-deoxyuridine) assays. Cells were fluorescently stained with EdU (red). Nuclei were stained with DAPI (blue). Scale bar, $50 \mu \mathrm{m}$. D and E) Cell cycle assay was analyzed using flow cytometry after transfected with siNC or sicircZMIZ1 in C4-2 and DU145 cells. Knockdown of circZMIZ1 induced an increase in G1 phase and a decrease in S phase. Data are presented as mean $\pm \mathrm{SD},{ }^{\star} \mathrm{p}<0.05,{ }^{* *} \mathrm{p}<0.01,{ }^{* *} \mathrm{p}<0.001$ (Student's t test).

STAT (PIAS) family members [24]. ZMIZ1 could increase transcriptional activity of other DNA-binding factors, such as androgen receptor (AR), SMAD3, STAT and p53 [14, $25,26]$, it has also been proved that ZMIZ1 co-localized with $A R$ and enhanced sumoylation of $A R$ in vivo [25]. In particular, it has been reported that ZMIZ1, as an oncogene [27], plays a promoting role in the growth of human PCa cell lines [13]. Another ZMIZ1 related circZMIZ1 was screened to be upregulated in $\mathrm{PCa}$ [17], however, the mechanism of circZMIZ1 in PCa has not been reported. 
There is a growing body of evidence indicating that circRNAs are not accidental by-products of pre-mRNA splicing, and more and more circRNAs have been found and reported to play pivotal roles during cancer cells progression [28], apoptosis [29], angiogenesis [30], autophagy [31], and so on. These results provide the idea that circRNAs have a great potential contribution to pathological states and/or as biomarkers of human diseases [32]. However, their clinical value remains largely unknown. In our study, we also found that circZMIZ1 was significantly upregulated in plasma of PCa patients and cell lines (LNCaP, C4-2 and DU145) by qRT-PCR. Due to their lariat structure, circZMIZ1 is much more stable than ZMIZ1 mRNA in PCa cell lines in a time- dependent manner, making its enrichment in peripheral blood of patients with PCa. These results suggest that the upregulated circZMIZ1 can be used as a novel diagnostic serum biomarker for the detection of PCa.

Notably, emerging evidence has shown that circRNAs can act as oncogenes or cancer suppressor genes in cancer. For example, circular RNA MYLK [9], hsa_circ_0009910 [33] and circ-10720 [8] promote cancer growth and metastasis, while circular RNA_LARP4 [34] and circular RNA cSMARCA5 [35] can inhibit tumor proliferation and invasion, and circRNAs can regulate gene expression and function as miRNA sponge in cancer progression [35-40]. To grasp the function of circZMIZ1, we knocked down the
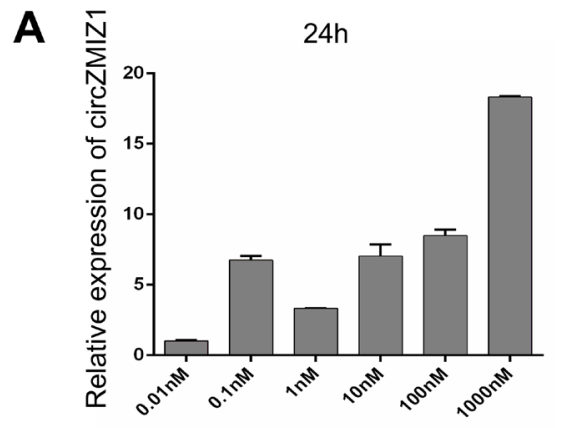

B
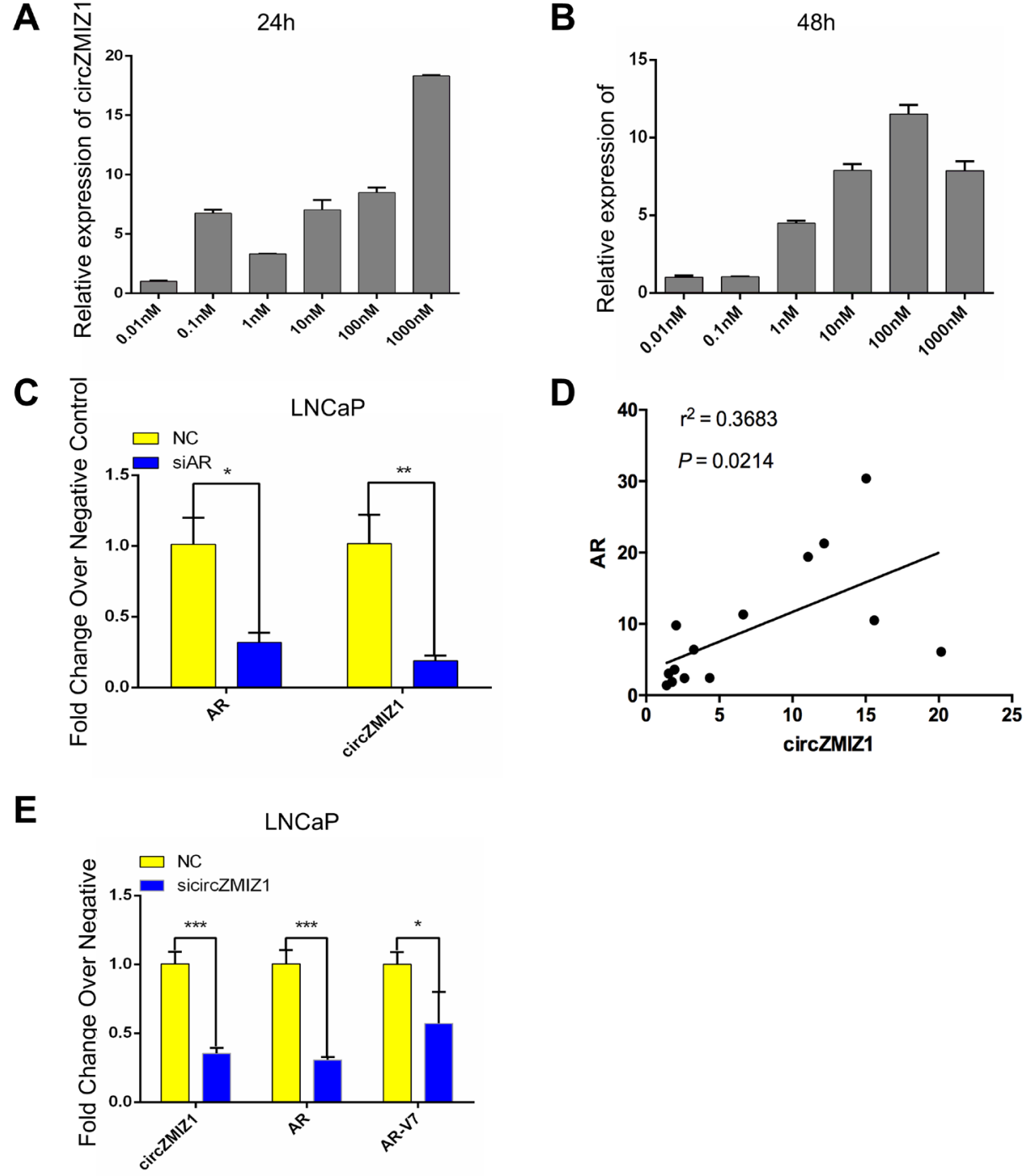

Figure 4. CircZMIZ1 is correlated with DHT and AR-V7. A and B) The level of circZMIZ1 was analyzed by qRT-PCR with androgen-depleted medium for $72 \mathrm{~h}$ and then treated with double hydrogen testosterone (DHT) $(0.01,0.1,1,10,100$, and $1000 \mathrm{nM})$ for $24 \mathrm{~h}$ and $48 \mathrm{~h}$. C) qRT-PCR analysis of circZMIZ1 expression detected after transfected with siAR in LNCaP. D) The relationship between AR and circZMIZ1 was analyzed with Pearson linear correlation. E) The expression of AR and AR-V7 was tested after treatment with sicircZMIZ1 by qRT-PCR. Data are presented as mean \pm SD, ${ }^{*} \mathbf{p}<0.05$, ${ }^{* *} \mathrm{p}<0.01,{ }^{* * *} \mathrm{p}<0.001$ (Student's $\mathrm{t}$ test). 
expression of circZMIZ1 in PCa cells using sicircZMIZ1 to explore its role in PCa progression. Our functional experiments results revealed that knockdown of circZMIZ1 inhibited DNA synthesis and cell proliferation in two different PCa cell lines. Our data suggested that circZMIZ1 may function as a novel candidate oncogene in PCa development and progression.

Recently, Huang et al. found that UAP56 (DDX39B) and URH49 (DDX39A) could control nuclear export of long and short circRNAs in human cells, respectively [41], and the distribution of circRNAs is mainly associated with its different biological function, in the cytoplasm, exonic circRNAs (ecircRNA) from exons could function as miRNAs and proteins sponge [42-44], interacting with proteins [45]. On the contrary, intronic circRNAs from introns, which largely localize in the nucleus, regulate the gene transcription $[42,43]$. Interestingly, we first found that circZMIZ1, which derives from exon almost equally localizes in the cytoplasm and nucleus, and its function in the nucleus correlated with AR transcription, however, the role of circZMIZ1 in the cytoplasm should be further investigated in future research.

The AR signaling axis plays a pivotal role in both androgen-sensitive PCa and CRPC, especially AR-V7 is strongly associated with castration resistance [46]. As mentioned before, ZMIZ1, as a transcriptional co-activator, can increase the transcriptional activity of AR, so we carried out qRT-PCR experiments to investigate the relationship between AR, AR-V7 and circZMIZ1 in LNCaP cell lines by transfected using sicircZMIZ1. The results showed that expression of AR and AR-V7 was significantly downregulated by treatment with sicircZMIZ1. Furthermore, our results suggest clearly that level of circZMIZ1 could be induced by DHT stimulation in LNCaP cells in a concentration dependent manner. In addition, the expression of AR was positively correlated with the expression of circZMIZ1 in LNCaP cell line, due to the small number of cases, coefficient of determination $\mathrm{r}^{2}$ is just 0.3683 . It implied circZMIZ1 involvement in the modulation of $\mathrm{AR}$ and AR-V7 expression, and this further raises the possibility of use of circZMIZ1 as a therapeutic target.

In conclusion, we showed that circZMIZ1 is upregulated in PCa patients' peripheral blood and PCa cells, and it could be induced by DHT, the expression of AR and AR-V7 could be silenced by sicircZMIZ1 treatment. We also demonstrated that circZMIZ1 acted as a novel candidate oncogene in prostate carcinoma by potentiating cell proliferation and promoting cell cycle. Furthermore, our findings provided novel insight into the biological function of circZMIZ1 that may act as a promising biomarker and an oncogenic circRNA with potential function for the treatment of patients with PCa.

Supplementary information is available in the online version of the paper.

\section{References}

[1] FITZMAURICE C, DICKER D, PAIN A, HAMAVID H, MORADI-LAKEH M et al. The Global Burden of Cancer 2013. JAMA Oncol 2015; 1: 505-527. https://doi.org/10.1001/jamaoncol.2015.0735

[2] ZHU Y, WANG HK, QU YY, YE DW. Prostate cancer in East Asia: evolving trend over the last decade. Asian J Androl 2015; 17: 48-57. https://doi.org/10.4103/1008-682X.132780

[3] CHEN W, SUN K, ZHENG R, ZENG H, ZHANG S et al. Cancer incidence and mortality in China, 2014. Chin J Cancer Res 2018; 30: 1-12. https://doi.org/10.21147/j.issn.10009604.2018.01.01

[4] AHMED KA, DAVIS BJ, WILSON TM, WISEMANi GA, FEDERSPIEL MJ et al. Progress in gene therapy for prostate cancer. Front Oncol 2012; 2: 172. https://doi.org/10.3389/ fonc.2012.00172

[5] BUBENDORF L, SCHOPFER A, WANGNER U, SAUTER $\mathrm{G}, \mathrm{MOCH} \mathrm{H}$ et al. Metastatic patterns of prostate cancer: an autopsy study of 1,589 patients. Hum Pathol 2000; 31: 578583. https://doi.org/10.1053/hp.2000.6698

[6] RAJPAR S, FIZAZI K. Bone targeted therapies in metastatic castration-resistant prostate cancer. Cancer J 2013; 19: 6670. https://doi.org/10.1097/PPO.0b013e31827f123e

[7] HAN B, CHAO J, YAO H. Circular RNA and its mechanisms in disease: From the bench to the clinic. Pharmacol Ther 2018; 187: 31-44. https://doi.org/10.1016/j.pharmthera.2018.01.010

[8] WANG Y, MO Y, GONG Z, YANG X, YANG M et al. Circular RNAs in human cancer. Mol Cancer 2017; 6: 25. https:// doi.org/10.1186/s12943-017-0598-7

[9] ZHONG Z, HUANG M, LV M, HE Y, DUAN C et al. Circular RNA MYLK as a competing endogenous RNA promotes bladder cancer progression through modulating VEGFA/ VEGFR2 signaling pathway. Cancer Lett 2017; 403: 305-317. https://doi.org/10.1016/j.canlet.2017.06.027

[10] MENG J, CHEN S, HAN JX, QIAN B, WANG XR et al. Twist1 Regulates Vimentin through Cul2 Circular RNA to Promote EMT in Hepatocellular Carcinoma. Cancer Res 2018; 78: 4150-4162. https://doi.org/10.1158/0008-5472. CAN-17-3009

[11] DU WW, YANG W, CHEN Y, WU ZK, FOSTER FS et al. Foxo3 circular RNA promotes cardiac senescence by modulating multiple factors associated with stress and senescence responses. Eur Heart J 2017; 38: 1402-1412. https://doi. org/10.1093/eurheartj/ehw001

[12] YOU X, VLATKOVIC I, BABIC A, WILL T, EPSTEIN I et al. Neural circular RNAs are derived from synaptic genes and regulated by development and plasticity. Nat Neurosci 2015; 18: 603-610. https://doi.org/10.1038/nn.3975

[13] PENG Y, LEE J, ZHU C, SUN Z. A novel role for protein inhibitor of activated STAT (PIAS) proteins in modulating the activity of Zimp7, a novel PIAS-like protein, in androgen receptor-mediated transcription. J Biol Chem 2010; 285: 11465-11475. https://doi.org/10.1074/jbc.M109.079327

[14] LI X, ZHU C, TU WH, YANG N, QIN H et al. ZMIZ1 preferably enhances the transcriptional activity of androgen receptor with short polyglutamine tract. PLoS One 2011; 6: e25040. https://doi.org/10.1371/journal.pone.0025040 
[15] LAU AJ, CHANG TK. Fetal bovine serum and human constitutive androstane receptor: evidence for activation of the SV23 splice variant by artemisinin, artemether, and arteether in a serum-free cell culture system. Toxicol Appl Pharmacol 2014; 277: 221-230. https://doi.org/10.1016/j. taap.2014.03.023

[16] SOBELL HM. Premeltons in DNA. J Struct Funct Genomics 2016; 17: 17-31. https://doi.org/10.1007/s10969-016-9202-4

[17] FEI T, CHEN Y, XIAO T, LI W, CATO L et al. Genomewide CRISPR screen identifies HNRNPL as a prostate cancer dependency regulating RNA splicing. Proc Natl Acad Sci U S A 2017; 114: E5207-5215. https://doi.org/10.1073/ pnas. 1617467114

[18] LORENZO PI, SAATCIOGLU F. Inhibition of apoptosis in prostate cancer cells by androgens is mediated through downregulation of c-Jun N-terminal kinase activation. Neoplasia 2008; 10: 418-428. https://doi.org/10.1593/neo.07985

[19] Lv D, Song X, Huang B, Yu YZ, Shu F et al. HMGB1 Promotes Prostate Cancer Development and Metastasis by Interacting with Brahma-Related Gene 1 and Activating the Akt Signaling Pathway. Theranostics 2019; 9: 5166-5182. https://doi. org/10.7150/thno.33972

[20] Lv D, Wu H, Xing R, Shu F, Lei B et al. HnRNP-L mediates bladder cancer progression by inhibiting apoptotic signaling and enhancing MAPK signaling pathways. Oncotarget. 2017; 8: 13586-13599. https://doi.org/10.18632/oncotarget.14600

[21] JECK WR, SORRENTINO JA, WANG K, SLEVIN MK, BURD CE et al. Circular RNAs are abundant, conserved, and associated with ALU repeats. RNA 2013; 19: 141-157. https://doi.org/10.1261/rna.035667.112

[22] HE J, XIE Q, XU H, LI J, LI Y. Circular RNAs and cancer. Cancer Lett 2017; 396: 138-144. https://doi.org/10.1016/j. canlet.2017.03.027

[23] DEL RE M, BIASCO E, CRUCITTA S, DEROSA L, ROFI E et al. The Detection of Androgen Receptor Splice Variant 7 in Plasma-derived Exosomal RNA Strongly Predicts Resistance to Hormonal Therapy in Metastatic Prostate Cancer Patients. Eur Urol 2017; 71: 680-687. https://doi.org/10.1016/j.eururo.2016.08.012

[24] PINNELL N, YAN R, CHO HJ, KEELEY T, MURAI MJ et al. The PIAS-like Coactivator Zmizl Is a Direct and Selective Cofactor of Notch1 in T Cell Development and Leukemia. Immunity 2015; 43: 870-883. https://doi.org/10.1016/j.immuni.2015.10.007

[25] SHARMA M, LI X, WANG Y, ZARNEGAR M, HUANG $\mathrm{CY}$ et al. hZimp10 is an androgen receptor co-activator and forms a complex with SUMO-1 at replication foci. EMBO J 2003; 22: 6101-6114. https://doi.org/10.1093/emboj/cdg585

[26] LEE J, BELIAKOFF J, SUN Z. The novel PIAS-like protein hZimp10 is a transcriptional co-activator of the p53 tumor suppressor. Nucleic Acids Res 2007; 35: 4523-4534. https:// doi.org/10.1093/nar/gkm476

[27] RAKOWSKI LA, GARAGIOLA DD, LI CM, DECKER M, CARUSO $S$ et al. Convergence of the ZMIZ1 and NOTCH1 pathways at C-MYC in acute $\mathrm{T}$ lymphoblastic leukemias. Cancer Res 2013; 73: 930-941. https://doi.org/10.1158/00085472.CAN-12-1389
[28] LU WY. Roles of the circular RNA circ-Foxo3 in breast cancer progression. Cell Cycle 2017; 16: 589-590. https://doi.org /10.1080/15384101.2017.1278935

[29] ZENG K, CHEN X, XU M, LIU X, HU X et al. CircHIPK3 promotes colorectal cancer growth and metastasis by sponging miR-7. Cell Death Dis 2018; 9: 417. https://doi. org/10.1038/s41419-018-0454-8

[30] LI Y, ZHENG F, XIAO X, XIE F, TAO D et al. CircHIPK3 sponges miR-558 to suppress heparanase expression in bladder cancer cells. EMBO Rep 2017; 18: 1646-1659. https:// doi.org/10.15252/embr.201643581

[31] DU WW, YANG W, LI X, AWAN FM, YANG Z et al. A circular RNA circ-DNMT1 enhances breast cancer progression by activating autophagy. Oncogene 2018; 37: 5829-5842. https://doi.org/10.1038/s41388-018-0369-y

[32] CHEN S, LI T, ZHAO Q, XIAO B, GUO J. Using circular RNA hsa_circ_0000190 as a new biomarker in the diagnosis of gastric cancer. Clin Chim Acta 2017; 466: 167-171. https://doi.org/10.1016/j.cca.2017.01.025

[33] DENG N, LI L, GAO J, ZHOU J, WANG Y et al. Hsa circ_0009910 promotes carcinogenesis by promoting the expression of miR-449a target IL6R in osteosarcoma. Biochem Biophys Res Commun 2018; 495: 189-196. https://doi. org/10.1016/j.bbrc.2017.11.028

[34] ZHANG J, LIU H, HOU L, WANG G, ZHANG R et al. Circular RNA_LARP4 inhibits cell proliferation and invasion of gastric cancer by sponging miR-424-5p and regulating LATS1 expression. Mol Cancer 2017; 16: 151. https://doi. org/10.1186/s12943-017-0719-3

[35] YU J, XU QG, WANG ZG, YANG Y, ZHANG L et al. Circular RNA cSMARCA5 inhibits growth and metastasis in hepatocellular carcinoma. J Hepatol 2018; 68: 1214-1227. https://doi.org/10.1016/j.jhep.2018.01.012

[36] ZHENG Q, BAO C, GUO W, LI S, CHEN J et al. Circular RNA profiling reveals an abundant circHIPK3 that regulates cell growth by sponging multiple miRNAs. Nat Commun 2016; 7: 11215. https://doi.org/10.1038/ncomms11215

[37] NG WL, MOHD MOHIDIN TB, SHUKLA K. Functional role of circular RNAs in cancer development and progression. RNA Biol 2018; 15: 995-1005. https://doi.org/10.1080/ 15476286.2018.1486659

[38] SUN HD, XU ZP, SUN ZQ, ZHU B, WANG Q et al. Downregulation of circPVRL3 promotes the proliferation and migration of gastric cancer cells. Sci Rep 2018; 8: 10111. https:// doi.org/10.1038/s41598-018-27837-9

[39] WANG R, ZHANG S, CHEN X, LI N, LI J et al. CircNT5E Acts as a Sponge of miR-422a to Promote Glioblastoma Tumorigenesis. Cancer Res 2018; 78: 4812-4825. https://doi. org/10.1158/0008-5472.CAN-18-0532

[40] YANG C, YUAN W, YANG X, LI P, WANG J et al. Circular RNA circ-ITCH inhibits bladder cancer progression by sponging miR-17/miR-224 and regulating p21, PTEN expression. Mol Cancer 2018; 17: 19. https://doi.org/10.1186/ s12943-018-0771-7

[41] HUANG C, LIANG D, TATOMER DC, WILUSZ JE. A length-dependent evolutionarily conserved pathway controls nuclear export of circular RNAs. Genes Dev 2018; 32: 639-644. https://doi.org/10.1101/gad.314856.118 
[42] LIU J, LIU T, WANG X, HE A. Circles reshaping the RNA world: from waste to treasure. Mol Cancer 2017; 16: 58. https://doi.org/10.1186/s12943-017-0630-y

[43] LEI K, BAI H, WEI Z, XIE C, WANG J et al. The mechanism and function of circular RNAs in human diseases. Exp Cell Res 2018; 368: 147-158. https://doi.org/10.1016/j. yexcr.2018.05.002

[44] ZHOU R, WU Y, WANG W, SU W, LIU Y et al. Circular RNAs (circRNAs) in cancer. Cancer Lett 2018; 425: 134-142. https://doi.org/10.1016/j.canlet.2018.03.035
[45] LI Z, HUANG C, BAO C, CHEN L, LIN M et al. Exon-intron circular RNAs regulate transcription in the nucleus. Nat Struct Mol Biol 2015; 22: 256-264. https://doi.org/10.1038/ nsmb.2959

[46] QU Y, DAI B, YE D, KONG Y, CHANG K et al. Constitutively active AR-V7 plays an essential role in the development and progression of castration-resistant prostate cancer. Sci Rep 2015; 5: 7654. https://doi.org/10.1038/srep07654 


\section{Upregulated circZMIZ1 promotes the proliferation of prostate cancer cells and is a valuable marker in plasma}

H. JIANG ${ }^{1, *}$, D. J. LV ${ }^{2,3, *}$, X. L. SONG ${ }^{4}$, C. WANG ${ }^{1}$, Y. Z. YU ${ }^{1}$, S. C. ZHAO ${ }^{1, *}$

\section{Supplementary Information}

\section{circBase}

\section{home list search}

table browser

blat

downloads

help

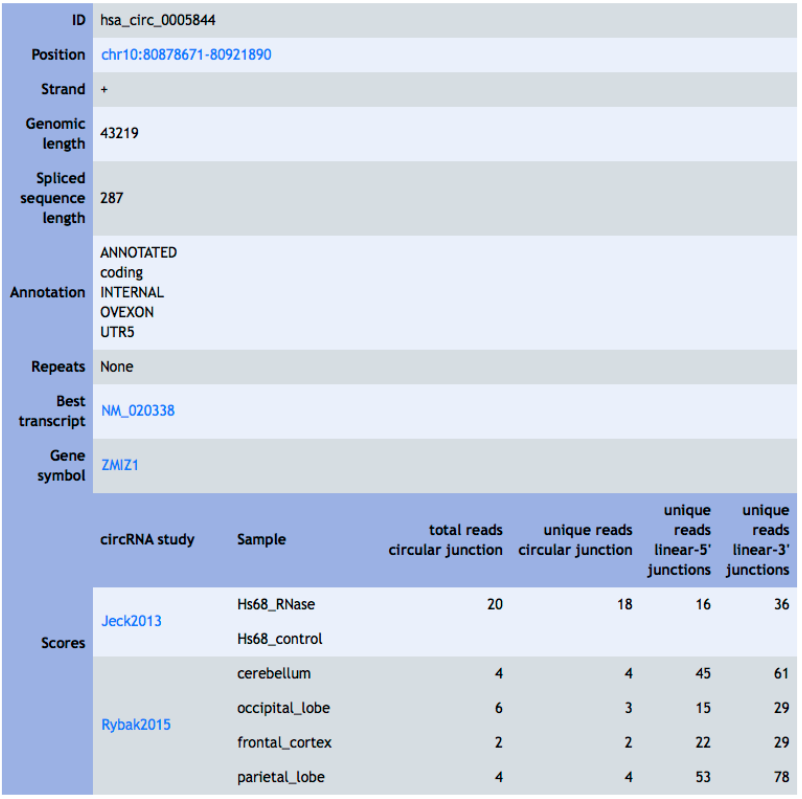

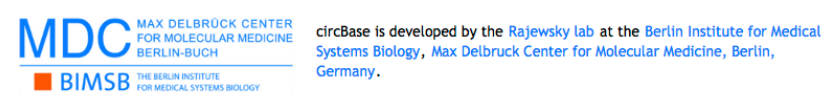

Supplementary Figure S1. circBase annotation for circZMIZ1 (ID: hsa circ_0005844).
Supplementary Table S1. The sequence of primers used for experiments in this study.

\begin{tabular}{ll}
\hline Primer Name for PCR & Sequence (5'-3') \\
\hline GAPDH-F & GGGAAACTGTGGCGTGAT \\
GAPDH-R & GAGTGGGTGTCGCTGTTGA \\
circZMIZ1-F & GATGGAGCTGGAGTGAGGTG \\
circZMIZ1-R & TCTGCAGAAGGACCAGGACT \\
linear ZMIZ1-F & TCTCAGGCACACCTCATCTG \\
linear ZMIZ1-R & GGCCCTCAGTTGTTCTCAAA \\
U6-F & CTCGCTTCGGCAGCACA \\
U6-R & AACGCTTCACGAATTTGCGT \\
AR-F & ACTCTGGCTTCACAGTTTGGA \\
AR-R & TTCCCTTCAGCGGCTCTTTT \\
AR-V7-F & AAAAGAGCCGCTGAAGGGAA \\
AR-V7-R & CCAACCCGGAATTTTTCTCCC \\
18sRNA-F & ACACGGACAGGATTGACAGA \\
18sRNA-R & GGACATCTAAGGGCATCACA \\
siRNAs & \\
sicircZMIZ1 & \\
siAR-F & GATCACTGAGGACTCACGG \\
siAR-R & CUGGGAAAGUCAAGCCCAUTT \\
FISH probes & AUGGGCUUGACUUUCCCAGTT \\
circZMIZ1 & \\
\hline
\end{tabular}

